\title{
Erratum to: Glutamate and Vivian Teichberg: a story about science, medicine, memory and love
}

\author{
Mia Levite Teichberg $\cdot$ Peter Riederer
}

Published online: 26 September 2014

(C) Springer-Verlag Wien 2014

\section{Erratum to: J Neural Transm (2014) 121:793-796 \\ DOI 10.1007/s00702-014-1250-y}

In the original version of this paper, the last name of the first author was incorrectly handled. For this reason, although the name appears correctly in the actual paper as published, it has been incorrectly referenced in abstract and indexing services as "ML Teichberg". It should read "M. Levite Teichberg".

The online version of the original article can be found under doi:10.1007/s00702-014-1250-y.

M. Levite Teichberg ( $\square)$

School of Behavioral Sciences, Academic College of Tel-Aviv-

Yaffo, Tel Aviv, Israel

e-mail: mialevite@mta.ac.il

M. Levite Teichberg

Faculty of Medicine, The Hebrew University of Jerusalem and

Hadassah Hebrew University Medical Center, Jerusalem, Israel

P. Riederer

Klinik und Poliklinik für Psychiatrie, Psychosomatik und

Psychotherapie des Universitätsklinikums Würzburg,

Füchsleinstrasse 15, 97080 Würzburg, Germany 